\title{
Non-attendance of occupational and physiotherapy appointments at Western Cape Rehabilitation Centre: a description of associated factors
}

\author{
Susan De Klerk, B OT (SU); DHT (UP); M OT (SU) https://orcid.org/0000-000 I-7639-93 I 9 \\ Senior Lecturer, Division of Occupational Therapy, Dept. Health and Rehabilitation Sciences, Faculty of Medicine and Health \\ Sciences, Stellenbosch University
}

*Lize Eloff, B OT (SU) https://orcid.org/0000-0003-1308-7486

Occupational Therapist, Elizabeth Ross District Hospital, Phuthaditjaba

*Zani Naudé, B OT (SU) https://orcid.org/0000-0002-5798-8908

Occupational Therapist, Sundays Valley Hospital, Kirkwood

*Andrea Boon, B OT (SU) https://orcid.org/0000-0002-4 | 44-3233

Occupational Therapist, Baragwanath Academic Hospital, Johannesburg

*Megan Carelse, B OT (SU) https://orcid.org/0000-0002-6080-5746

Occupational Therapist, Cofimvaba Hospital, Cofimvaba

* Michaela Steward, B OT (SU) https://orcid.org/0000-0003-28 I 0-4787

Occupational Therapist, Empilisweni Hospital, Sterkspruit

* Minal Zaidi, B OT (SU) wane District Health Services, Pretoria

*All undergraduate students at the University of Stellenbosch at the time of the study

Introduction: Occupational therapists and physiotherapists use outpatient follow-up appointments to continue and monitor the effectiveness and outcome of therapy interventions. Attendance of follow-up appointments is essential, as non-attendance has negative implications for both the patient and the healthcare facility.

Methodology: This retrospective, cross-sectional study made use of a period sample of all outpatients with scheduled appointments between January and December $2017(n=837)$ at the Western Cape Rehabilitation Centre (WCRC). Children under the age of I8 years were excluded. Descriptive statistics were used to describe the identified variables of the sample. Logistic regression was used to determine the adjusted odds ratio for the association between non-attendances and identified covariates.

Results: The sample population of 837 patients, included 516 attenders and 321 non-attenders. Factors that had an association with non-attendance included hospital classification, diagnostic category and impairment according to ICD I0 coding $(p \leq 0.05)$.

Conclusion: This article describe factors associated with non-attendance of outpatients to scheduled occupational therapy and physiotherapy appointments at the WCRC. Further research is needed to determine the reasons for non-attendance at institutions such as WCRC which will assist in the implementation of strategies to reduce high non-attendance rates.

Key words: non-attendance, occupational and physiotherapy appointments, outpatient appointments

\section{INTRODUCTION}

The Western Cape Rehabilitation Centre (WCRC) is a Western Cape Department of Health Specialised Health Care Facility, situated in Mitchells Plain, Cape Town, with a maximum capacity of 240 beds and daily outpatient clinics. Physical conditions such as stroke, traumatic brain injury or spinal cord injury, often require inpatient and outpatient rehabilitation in settings such as the WCRC. For effective treatment, a multidisciplinary team approach to rehabilitation is preferred. Occupational and physiotherapists offer rehabilitation programmes to patients following injury or disease, as inpatients and/or outpatients'. Intervention entails a regular review of the patient's progress, to monitor the effectiveness of intervention and to measure the outcome thereof ${ }^{2}$. It is therefore crucial for occupational and physiotherapists to monitor patient progress and offer further input. WCRC staff and management have expressed concern about non-attendance of occupational and physiotherapy followup outpatient appointments at this institution. Non-attendance of outpatient appointments has been studied globally with a variety of factors reported to be associated with non-attendance ${ }^{3-7}$. This phenomenon has however not been studied in this context and an understanding of the factors associated with non-attendance could assist this institution and others to make informed decisions about service delivery and prioritisation.

This study therefore aimed to describe the factors associated 
with non-attendance of patients that had scheduled outpatient follow-up occupational therapy and physiotherapy appointments at the WCRC. The objectives of the study were I) to describe the identified characteristic factors of both attendees and non-attendees and 2) to determine the association between non-attendance and the identified factors.

\section{LITERATURE REVIEW}

Occupational therapists and physiotherapists form part of a multidisciplinary team and are involved in the intervention of patients with physical disabilities. Patients with physical disabilities as a result of cerebrovascular accidents (CVA) and spinal cord injuries may experience long term effects following the diagnosis. Langhorne, Bernhardt and Kwakkel ${ }^{8}$ report that despite developments that have been made with regards to the medical management of patients following CVA, most post-stroke care will continue to rely on rehabilitation interventions. This is the same for patients with spinal cord injuries. These rehabilitation interventions can take place in an inpatient setting but as SchultzKrohn and Pendleton ${ }^{2}$ explain, the continuum of care leads to outpatient practice settings. On an outpatient level, occupational therapy and physiotherapy is now directed at the restoration of skill, the adaptation of activities, prevention of complications and enhancing function. Variability with regards to the therapy services provided at the outpatient level, is extensive. Patient needs as well as services offered at the institution influence the frequency of occupational therapy and physiotherapy services. Therapy can therefore occur on a weekly, monthly or yearly basis ${ }^{2}$. Patient attendance and compliance to therapy is essential in maintaining the effectiveness of the therapeutic intervention, particularly in the early stages after discharge.

Non-attendance of scheduled follow up appointments negatively impacts the patients but it also has negative implications for the institution ${ }^{3}$. Non-attendance may lead to possible functional deterioration that if not detected early, negatively affects overall clinical outcomes ${ }^{4}$, causes delayed recovery time and poor participation prospects ${ }^{5}$. Rhoda, Mpofu and De Weerdt ${ }^{6}$ aimed to determine the activity limitations experienced by stroke patients, attending outpatient facilities in the Western Cape. In this study, patients that attended follow-up appointments demonstrated better community and functional engagement in daily activities, than those who failed to attend ${ }^{6}$. Similar comparisons were made in developed contexts between stroke patients that received outpatient follow-up in rehabilitation hospitals or nursing homes and those who did not ${ }^{7}$. Patients who were compliant with rehabilitation were able to better engage in their activities of daily living and community transition was more effective?. Similarly it was found that patients who did not attend their follow-up appointments were at higher risk of developing secondary complications such as pressure sores, contractures, urinary tract infections and also psychosocial adjustment problems such as depression?. As a result, failure to attend was found to be associated with great personal and social costs to individuals as a result of having to manage secondary complications ${ }^{10}$.

Non-attendance contributes to the financial burden on the institution as occupational and physiotherapists have to adapt or terminate patient treatment regimens ${ }^{\prime \prime}$. Non-attendance has also been found to be associated with the misuse of hospital resources such as personnel time, ward capacity and patients' waiting times as well as inefficient time use of health care practitioners ${ }^{12,13}$. Results from a study conducted at an outpatient physiotherapy clinic, in a teaching hospital in Nigeria, demonstrated that nonattendance directly influences the productivity of the service providers $^{14}$. In addition, institutions have to compensate for missed appointments by rescheduling appointments, which was found to be problematic. As a result, institutions may also be delayed in efficient assessment of new patients ${ }^{15}$.

Ellis and Jenkins ${ }^{16}$ found specific days of the week to impact outpatient non-attendance at medical healthcare facilities. Appointments scheduled on a Monday had higher rates of outpatient non-attendance compared to appointments scheduled on a Friday $^{16}$. In contrast with Ellis and Jenkins ${ }^{16}$, a systematic review conducted by George and Rubin " yielded alternate results. They reviewed literature in relation to non-attendance at primary health care institutions as well as the implications thereof, specifically in the United States of America (USA) and the United Kingdom $(\mathrm{UK})^{\prime \prime}$. Results of their study indicated that patients were more likely to not attend on a Friday". Throughout the literature reviewed it was found that a patient's age was a predictor of patient non-attendance. Younger people were less likely to attend their appointments ${ }^{13,17-20}$.

A randomised control trial by Worcester et al. ${ }^{19}$ on factors associated with non-attendance at a secondary prevention clinic for cardiac patients, found females were more likely to be nonattenders as compared to males. In agreement with this Mbada et al. ${ }^{20}$ found that females had a higher rate of non-attendance in their retrospective audit of the impact of missed appointments for outpatient physiotherapy in Nigeria. In contrast to this a prospective cohort study conducted in the UK, by Hamilton, Round and Sharp ${ }^{17}$ and a study by Maskew, MacPhail et al, ${ }^{21}$ that investigated factors and challenges that affect attendance of South African patients undergoing antiretroviral therapy, both found that males were at higher risk of non-attendance.

The results from research conducted at an outpatient gastroenterology clinic, in the USA indicated that individuals who are single are less likely to attend follow-up appointments, in comparison to married individuals ${ }^{22}$. Similarly, research in New York City, USA ${ }^{23}$ studied patient compliance with short term treatment for lower back pain, and found that patients who were single or unmarried, were less likely to attend ${ }^{23}$.

Mitchell and Selmes ${ }^{18}$ reviewed the extent of and predictors of non-attendance in individuals with mental health disorders presenting at primary and secondary healthcare facilities. Factors that were associated with non-attendance included demographic factors, such as lower socioeconomic status and the absence of health insurance ${ }^{18}$. This is confirmed by Hamilton, Round and Sharp ${ }^{17}$ and George and Rubin ${ }^{\prime \prime}$. Sharp and Hamilton ${ }^{24}$ described that non-attendance could be attributed to patients not receiving information in their home language, learning difficulties or diverse cultural backgrounds ${ }^{24}$. Maskew et al. ${ }^{21}$ identified financial constraints to be the main contributing reason for patient nonattendance. In contrast, a case-control study, conducted in the UK, highlighted that socio-demographic variations such as age and gender among patients did not significantly influence attendance rates at a periodontal clinic ${ }^{25}$.

It is important to consider the contribution that has been made with regards to research investigating the factors associated with non-attendance in the South African context. Ngwenya, van Zyl and Webb ${ }^{26}$ investigated the factors associated with non-attendance of outpatient appointments at a Diabetic Clinic at Kalafong Hospital in Gauteng, South Africa. The results of the study showed that the distance that the patients had to travel to the clinic influenced whether they attended or not ${ }^{26}$. Patients that were located further from the clinic were more likely to miss appointments ${ }^{26}$. This is in agreement with findings from an international study done by Mitchell and Selmes in the UK ${ }^{18}$. Furthermore, patients were less likely to attend if they did not have their own transport ${ }^{26}$. A qualitative study which explored the factors associated with non-compliance and non-attendance in various Cape Town health care facilities found that factors such as the accessibility of public transport services, interaction with staff members, family/caregivers involvement in rehabilitation as well as the necessary information with regards to treatment being available hindered patient treatment compliance which increased the risk of non-attendance ${ }^{27}$. The study reported that a main concern with the public transport systems in Cape Town is its inadequacy with regards to accessibility for persons with disabilities as well 
as the overcrowding within the available systems ${ }^{27}$. The distance that patients have to travel to the facilities and the availability of transport is thus a factor associated with non-attendance. Similarly, in a study by Lieberman, Meana and Stewart ${ }^{28}$ conducted in Canada found that problems with transportation was one of the main reasons for both males and females not to attend cardiac rehabilitation programmes ${ }^{28}$.

The literature review highlights factors that can be associated with patient non-attendance of outpatient appointments which include but is not limited to: gender, age, marital status, socioeconomic factors and distances travelled.

\section{METHOD}

This retrospective cross-sectional study, within a positivist paradigm was conducted on previously recorded data of outpatients that attended and failed to attend occupational therapy and physiotherapy outpatient clinics at the WCRC between January and December 2017. Non-attendance was used as the outcome for analysis. Variables (factors) recorded for the analysis were based on the review of the literature but also on the pragmatic consideration of what was captured by the institution (WCRC) for the sample during the time period (January to December 2017). All recorded variables can be seen in Tables I to V (pages 56 - 60).

\section{Study context}

WCRC is a specialised rehabilitation centre situated in Mitchell's Plain, Cape Town, South Africa. Rehabilitation is primarily directed at individuals with physical impairments and rehabilitation can occur on both an inpatient and outpatient basis. The centre accepts referrals from all levels of healthcare institutions as well as through self-referral. At WCRC, patients receive specialised rehabilitation towards the promotion of functional independence and reintegration into their communities ${ }^{29}$

\section{Participants and sampling}

A census was used to study every unit in a population of both attenders and non-attenders of occupational therapy and physiotherapy appointments during the course of $2017^{30}$. Sample size was therefore not predetermined as all patients during the time period were included if they have both attended or failed to attend either occupational therapy and/or physiotherapy outpatients appointments between January and December 20 I7.Children under the age of 18 were not included in the study.

\section{Data collection}

Data were collected in March 2018 upon receiving ethical clearance from the Undergraduate Health Research Ethics Committee of Stellenbosch University (ethics reference number: U I 7/I0/054) as well as authorisation form WCRC. WCRC uses the Clinicom system to keep patient records. Clinicom is a hospital information system which stores patient information electronically. Comprehensive patient information is therefore readily accessible to hospital personnel. Data collection took place at WCRC on 26 to 29 March and I 3 April, 20 I8. The researchers used Clinicom and patient medical files to extract predetermined variables available through the Clinicom system, including but not limited to age, gender, hospital classification, employment status and time of the year of scheduled appointment (seasons). Data were recorded on an excel spreadsheet and checked for accuracy.

Due to the retrospective nature of the research, patient anonymity was ensured through application of a waiver of consent. Anonymity allowed for information obtained to be shared without the concern of identifying participants. Identifying factors were categorised into direct and indirect identifiers. Direct factors include names, home address and pictures of the participants and indirect factors were factors that could be linked back to a participant for example age and salary ${ }^{31}$. Therefore it was essential for the researchers to categorise information such as age into groups to ensure participants were not identified. It was also important for the researchers to ensure anonymity of the occupational therapists, physiotherapists and other personnel at WCRC working in the outpatient department in order to protect their identity.

\section{Data analysis}

Descriptive statistics, namely frequencies and percentages were used to describe the variables. Logistic regression was used to describe whether the presence of a risk factor (identified variable) increases the odds of the given outcome namely non-attendance. The researchers determined the association of the identified variables with non-attendance and whether the variables influenced the predictability or odds of patients not attending their scheduled appointments at WCRC. Odds ratios (OR) were included and identified to be significant if the value of the ratio fell within the confidence interval and corresponded with a $p$-value of less than $5 \%(\mathrm{p}<0.05) . \mathrm{OR}>\mathrm{I}$ indicate that the variable is associated with higher odds of non-attendance whereas $O R<I$ indicate that the variable is associated with lower odds of non-attendance ${ }^{32}$. Analysis were performed at a $5 \%$ significance level with the assistance of a statistician in Stata, version 14.

\section{RESULTS}

The sample population included 837 patients of which 516 were attenders and $32 \mathrm{I}$ non-attenders, identified on the basis of whether they attended their most recent scheduled appointment. The mean age of the sample were in the $25^{\text {th }}$ percentile range ( $30-39$ years). Descriptive statistics, namely frequencies and percentages were used to describe the variables, seen in Tables I - IV.

\section{Table I: Participant demographic factors}

\begin{tabular}{|l|c|c|c|c|c|}
\hline \multirow{2}{*}{ Variable } & \multicolumn{2}{|c|}{ Non-Attenders } & \multicolumn{2}{c|}{ Attenders } & Total \\
\cline { 2 - 6 } & $\mathbf{N}$ & $\%$ & $\mathbf{N}$ & $\%$ & $\mathbf{N}$ \\
\hline Gender & & & & & \\
\hline Male & 249 & $40.16 \%$ & 371 & $59.84 \%$ & 620 \\
\hline Female & 72 & $33.18 \%$ & 145 & $66.82 \%$ & 217 \\
\hline Total & $\mathbf{3 2 1}$ & $\mathbf{3 8 . 3 5 \%}$ & $\mathbf{5 1 6}$ & $\mathbf{6 1 . 6 5 \%}$ & $\mathbf{8 3 7}$ \\
\hline Marital status & & & & & \\
\hline Married & 83 & $34.73 \%$ & 156 & $65.27 \%$ & 239 \\
\hline Unmarried & 216 & $40.00 \%$ & 324 & $60.00 \%$ & 540 \\
\hline Divorced & 8 & $30.77 \%$ & 18 & $69.23 \%$ & 26 \\
\hline Widowed & 14 & $43.75 \%$ & 18 & $56.25 \%$ & 32 \\
\hline Total & $\mathbf{3 2 1}$ & $\mathbf{3 8 . 3 5 \%}$ & $\mathbf{5 1 6}$ & $\mathbf{6 1 . 6 5 \%}$ & $\mathbf{8 3 7}$ \\
\hline
\end{tabular}

Attendance was greater in autumn (35\%) as compared to spring (16\%). Non-attendance was greater in spring (38\%) as compared to autumn (19\%). Summer had the same rate for attendance and non-attendance $(23 \%)$ and in winter, attendance rates $(26 \%)$ were higher than non-attendance rates (20\%).

The highest non-attendance rates occurred in November (14\%) compared to December, which had the lowest non-attendance rate (4\%). Additionally, attendance rates were higher in January (8\%), February (10\%), March (13\%), April (9\%), May (I4\%), June (19\%), August (4\%) and December (5\%). Non-attendance rates however, were higher in the remaining months of July $(10 \%)$, September (I2\%), October (13\%) and November (14\%) as compared to attendance in these months.

With regards to the days of the week attendance was higher on Fridays (27\%) compared to Mondays (I $2 \%)$. Non-attendance was greater on Thursdays (29\%), compared to Mondays (15\%). Nonattendance was less on a Friday (16\%). There were no statistically significant difference between attendance and non-attendance in relation to the weeks of the month. During the fourth week of the month attendance rates $(31 \%)$ was greater and during the first week of the month non-attendance $(24 \%)$ rates were higher. 
Table II: Participant Socio - economic factors

\begin{tabular}{|c|c|c|c|c|c|}
\hline \multirow{2}{*}{ Variable } & \multicolumn{2}{|c|}{ Non-Attenders } & \multicolumn{2}{|c|}{ Attenders } & \multirow{2}{*}{$\begin{array}{c}\text { Total } \\
\mathbf{N}\end{array}$} \\
\hline & $\mathbf{N}$ & $\%$ & $\mathbf{N}$ & $\%$ & \\
\hline \multicolumn{6}{|c|}{ Number of dependents } \\
\hline 0 & 195 & $37.72 \%$ & 332 & $62.28 \%$ & 517 \\
\hline 1 & 52 & $42.62 \%$ & 70 & $57.38 \%$ & 122 \\
\hline 2 & 35 & $35.00 \%$ & 65 & $65.00 \%$ & 100 \\
\hline 3 & 25 & $39.06 \%$ & 39 & $60.94 \%$ & 64 \\
\hline 4 & 7 & $33.33 \%$ & 14 & $66.67 \%$ & 21 \\
\hline 5 & 5 & $50.00 \%$ & 5 & $50.00 \%$ & 10 \\
\hline$>5$ & 2 & $66.67 \%$ & I & $33.33 \%$ & 3 \\
\hline Total & 321 & $38.35 \%$ & 516 & $61.65 \%$ & 837 \\
\hline \multicolumn{6}{|l|}{ Employment status } \\
\hline Employed & 47 & $33.10 \%$ & 95 & $66.90 \%$ & 142 \\
\hline Unemployed & 262 & $40.06 \%$ & 392 & $59.94 \%$ & 654 \\
\hline Retired & 12 & $29.27 \%$ & 29 & $70.73 \%$ & 41 \\
\hline Total & 321 & $38.35 \%$ & 516 & $61.65 \%$ & 837 \\
\hline \multicolumn{6}{|c|}{ Hospital Classification } \\
\hline $\mathrm{HO}$ & 193 & $40.38 \%$ & 285 & $59.62 \%$ & 478 \\
\hline $\mathrm{HI}$ & 72 & $47.68 \%$ & 79 & $52.32 \%$ & 151 \\
\hline $\mathrm{H} 2$ & 5 & $15.15 \%$ & 28 & $84.85 \%$ & 33 \\
\hline $\mathrm{H} 3$ & 4 & $21.05 \%$ & 15 & $78.95 \%$ & 19 \\
\hline$* \mathrm{RAF}$ & 29 & $35.37 \%$ & 53 & $64.63 \%$ & 82 \\
\hline Medical-Aid & 14 & $21.88 \%$ & 50 & $78.13 \%$ & 64 \\
\hline ***COIDA & 2 & $40.00 \%$ & 3 & $60.00 \%$ & 5 \\
\hline State department & 1 & $50.00 \%$ & I & $50.00 \%$ & 2 \\
\hline Other & $\mathrm{I}$ & $33.33 \%$ & 2 & $66.67 \%$ & 3 \\
\hline Total & 321 & $38.35 \%$ & 516 & $61.65 \%$ & 837 \\
\hline
\end{tabular}

Table III: Participant diagnostic factors

\begin{tabular}{|c|c|c|c|c|c|}
\hline \multirow{2}{*}{ Variable } & \multicolumn{2}{|c|}{ Non-Attenders } & \multicolumn{2}{|c|}{ Attenders } & \multirow{2}{*}{$\begin{array}{c}\text { Total } \\
\mathbf{N}\end{array}$} \\
\hline & $\mathbf{N}$ & $\%$ & $\mathbf{N}$ & $\%$ & \\
\hline \multicolumn{6}{|l|}{ Diagnostic category } \\
\hline Spinal cord injury & 227 & $44.51 \%$ & 283 & $55.49 \%$ & 510 \\
\hline $\begin{array}{l}\text { Cerebrovascular } \\
\text { accident }\end{array}$ & 17 & $17.71 \%$ & 79 & $82.29 \%$ & 96 \\
\hline Upper limb injury & 0 & $0.00 \%$ & 1 & $100 \%$ & 1 \\
\hline Lower limb injury & 36 & $45.00 \%$ & 44 & $55.00 \%$ & 80 \\
\hline Traumatic brain injury & 6 & $27.27 \%$ & 16 & $72.73 \%$ & 22 \\
\hline Other & 35 & $27.34 \%$ & 93 & $72.66 \%$ & 128 \\
\hline Total & 321 & $38.35 \%$ & 516 & $61.65 \%$ & 837 \\
\hline \multicolumn{6}{|l|}{$\begin{array}{l}\text { ICD I0 coding of } \\
\text { impairment }\end{array}$} \\
\hline Tetra (G82.5) & 79 & $38.35 \%$ & 127 & $61.65 \%$ & 206 \\
\hline Para (G82.2) & 155 & $48.14 \%$ & 167 & $51.86 \%$ & 322 \\
\hline Hemi (G8I.9 & 14 & $16.67 \%$ & 70 & $83.33 \%$ & 84 \\
\hline Other & 73 & $32.44 \%$ & 152 & $67.56 \%$ & 225 \\
\hline Total & 321 & $38.35 \%$ & 516 & $61.65 \%$ & 837 \\
\hline
\end{tabular}


... Table III continued from page 57

\begin{tabular}{|c|c|c|c|c|c|}
\hline $\begin{array}{l}\text { Mechanism of } \\
\text { injury }\end{array}$ & & & & & \\
\hline $\begin{array}{l}\text { Motor vehicle } \\
\text { accident }\end{array}$ & 63 & $36.00 \%$ & 112 & $64.00 \%$ & 175 \\
\hline Gunshot wound & 81 & $49.09 \%$ & 84 & $50.91 \%$ & 165 \\
\hline Stabbing & 41 & $53.25 \%$ & 36 & $46.75 \%$ & 77 \\
\hline $\begin{array}{l}\text { Sport and recreation } \\
\text { injury }\end{array}$ & 9 & $45.00 \%$ & II & $55.00 \%$ & 20 \\
\hline Other & 97 & $35.79 \%$ & 174 & $64.21 \%$ & 271 \\
\hline N/A & 30 & $23.26 \%$ & 99 & $76.74 \%$ & 129 \\
\hline Total & 32 & $38.35 \%$ & 516 & $61.65 \%$ & 837 \\
\hline \multicolumn{6}{|l|}{ Comorbidities } \\
\hline Hypertension & 12 & $27.27 \%$ & 32 & $72.73 \%$ & 44 \\
\hline $\begin{array}{l}\text { Human } \\
\text { Immunodeficiency } \\
\text { Virus }\end{array}$ & 5 & $29.41 \%$ & 12 & $70.59 \%$ & 17 \\
\hline Diabetes Mellitus & 8 & $57.14 \%$ & 6 & $42.86 \%$ & 14 \\
\hline Overweight & 2 & $22.22 \%$ & 7 & $77.78 \%$ & 9 \\
\hline Underweight & 4 & $66.67 \%$ & 2 & $33.33 \%$ & 6 \\
\hline Smoker & 15 & $32.61 \%$ & 31 & $67.39 \%$ & 46 \\
\hline $\begin{array}{l}\text { Other substance } \\
\text { abuse }\end{array}$ & 6 & $42.86 \%$ & 8 & $57.14 \%$ & 14 \\
\hline Malignancy & 1 & $100 \%$ & 0 & $0.00 \%$ & 1 \\
\hline Psychiatric conditions & $\mathrm{I}$ & $16.67 \%$ & 5 & $83.33 \%$ & 6 \\
\hline Active Tuberculosis & 4 & $50.00 \%$ & 4 & $50.00 \%$ & 8 \\
\hline Other & 19 & 42.22 & 26 & $57.78 \%$ & 45 \\
\hline Multiple & 46 & $32.39 \%$ & 96 & $67.61 \%$ & 142 \\
\hline N/A & 87 & $45.31 \%$ & 105 & $54.69 \%$ & 192 \\
\hline None & 111 & $37.88 \%$ & 182 & $62.12 \%$ & 293 \\
\hline Total & 321 & 38.35 & 516 & $61.65 \%$ & 837 \\
\hline
\end{tabular}

Table IV: Participant geographical factors

\begin{tabular}{|c|c|c|c|c|c|}
\hline \multirow{2}{*}{ Variable } & \multicolumn{2}{|c|}{ Non-Attenders } & \multicolumn{2}{|c|}{ Attenders } & \multirow{2}{*}{$\begin{array}{c}\text { Total } \\
\mathbf{N}\end{array}$} \\
\hline & $\mathbf{N}$ & $\%$ & $\mathbf{N}$ & $\%$ & \\
\hline \multicolumn{6}{|c|}{$\begin{array}{l}\text { District within which patient resides if from Western } \\
\text { Cape (average distance patient has to travel) }\end{array}$} \\
\hline Cape Metropole (I0km) & 236 & $35.01 \%$ & 438 & $64.99 \%$ & 674 \\
\hline West Coast $(100 \mathrm{~km})$ & 19 & $61.29 \%$ & 12 & $38.71 \%$ & 31 \\
\hline Cape Winelands (100km) & 32 & $58.18 \%$ & 23 & $41.82 \%$ & 55 \\
\hline Overberg (I20km) & 23 & $51.11 \%$ & 22 & $48.89 \%$ & 45 \\
\hline Eden $(400 \mathrm{~km})$ & 4 & $30.77 \%$ & 9 & $69.23 \%$ & 13 \\
\hline Central Karoo (450km) & 4 & $30.77 \%$ & 9 & $69.23 \%$ & 13 \\
\hline$* N / A$ & 3 & $50.00 \%$ & 3 & $50.00 \%$ & 6 \\
\hline Total & 321 & $38.35 \%$ & 516 & $61.65 \%$ & 837 \\
\hline \multicolumn{6}{|c|}{$\begin{array}{l}\text { Metro health sub district patient resides (if from Cape } \\
\text { Metropole) }\end{array}$} \\
\hline Western & 21 & $33.87 \%$ & 41 & $66.13 \%$ & 62 \\
\hline Northern & 22 & $33.33 \%$ & 44 & $66.67 \%$ & 66 \\
\hline Tygerberg & 23 & $30.67 \%$ & 52 & $69.33 \%$ & 75 \\
\hline Klipfontein & 11 & $44.00 \%$ & 14 & $56.00 \%$ & 25 \\
\hline
\end{tabular}


... Table IV continued from page 58

\begin{tabular}{|c|c|c|c|c|c|}
\hline Mitchell's Plain & 51 & $38.06 \%$ & 83 & $61.94 \%$ & 134 \\
\hline Khayelitsha & 28 & $38.36 \%$ & 45 & $61.64 \%$ & 73 \\
\hline Eastern & 52 & $37.14 \%$ & 88 & $62.86 \%$ & 140 \\
\hline Southern & 29 & $29.00 \%$ & 71 & $71.00 \%$ & 100 \\
\hline *N/A & 84 & $51.85 \%$ & 78 & $48.15 \%$ & 162 \\
\hline Total & 321 & $38.35 \%$ & 516 & $61.65 \%$ & 837 \\
\hline \multicolumn{6}{|c|}{ Province patient resides in if not from Western Cape } \\
\hline Eastern Cape & I & $50.00 \%$ & 1 & $50.00 \%$ & 2 \\
\hline Northern Cape & 3 & $50.00 \%$ & 3 & $50.00 \%$ & 6 \\
\hline *N/A & 317 & $38.24 \%$ & 512 & $61.76 \%$ & 829 \\
\hline Total & 321 & $38.35 \%$ & 516 & $61.65 \%$ & 837 \\
\hline \multicolumn{6}{|l|}{ Source of referral } \\
\hline Intermediate Care & 7 & $36.84 \%$ & 12 & $63.16 \%$ & 19 \\
\hline Primary Level Services & 31 & $36.47 \%$ & 54 & $63.53 \%$ & 85 \\
\hline Secondary Level Services & 16 & $35.56 \%$ & 29 & $64.44 \%$ & 45 \\
\hline Tertiary Level Services & 125 & $39.56 \%$ & 191 & $60.44 \%$ & 316 \\
\hline Private Sector & 7 & $24.14 \%$ & 22 & $75.86 \%$ & 29 \\
\hline WCRC outpatient department & 58 & $35.80 \%$ & 104 & $64.20 \%$ & 162 \\
\hline Self-Referral/Word of Mouth & 65 & $48.51 \%$ & 69 & $51.49 \%$ & 134 \\
\hline Other/Re-admissions & 12 & $25.53 \%$ & 35 & $74.47 \%$ & 47 \\
\hline Total & 321 & $38.35 \%$ & 516 & $61.65 \%$ & 838 \\
\hline
\end{tabular}

Table V: Logistic regression with non-attendance as outcome

\begin{tabular}{|c|c|c|c|}
\hline Variable & Odds ratio & ( $95 \%$ Confidence Interval) & p-value \\
\hline Gender & & & 0.067 \\
\hline Female & 0.740 & $(0.534-1.024)$ & 0.069 \\
\hline Male & 0.671 & $(0.57 \mathrm{I}-0.788)$ & 0.000 \\
\hline Employment status & & & 0.137 \\
\hline Employed & 0.740 & $(0.504-1.086)$ & 0.124 \\
\hline Retired & 0.619 & $(0.310-1.235)$ & 0.174 \\
\hline Unemployed & 0.668 & $(0.57 I-0.782)$ & 0.000 \\
\hline Hospital classification & & & 0.001 \\
\hline $\mathrm{HO}$ & 0.677 & $(0.564-0.813)$ & 0.000 \\
\hline $\mathrm{HI}$ & 1.345 & $(0.932-1.944)$ & 0.114 \\
\hline $\mathrm{H} 2$ & 0.264 & $(0.100-0.695)$ & 0.007 \\
\hline $\mathrm{H} 3$ & 0.394 & $(0.129-1.204)$ & 0.102 \\
\hline RAF & 0.807 & $(0.496-1.317)$ & 0.392 \\
\hline Medical-Aid & 0.413 & $(0.222-0.769)$ & 0.005 \\
\hline COIDA & 0.984 & $(0.163-5.947)$ & 0.986 \\
\hline State department & 1.476 & $(0.092-23.75 I)$ & 0.783 \\
\hline Other & 0.738 & $(0.066-8.199)$ & 0.805 \\
\hline Diagnostic category & & & 0.000 \\
\hline Spinal cord injury & 0.802 & $(0.674-0.955)$ & 0.013 \\
\hline Cerebrovascular accident & 0.268 & $(0.154-0.466)$ & 0.000 \\
\hline Upper limb injury & $\mathrm{I}$ & (empty)* & (empty)* \\
\hline Lower limb injury & 1.020 & $(0.635-1.638)$ & 0.935 \\
\hline
\end{tabular}


... Table $\mathbf{V}$ continued from page $\mathbf{5 9}$

\begin{tabular}{|l|l|l|l|}
\hline Traumatic brain injury & 0.468 & $(0.180-1.214 \mathrm{I})$ & 0.118 \\
\hline Other & 0.469 & $(0.306-0.7185)$ & 0.000 \\
\hline Impairment according to ICD I0 coding & & & 0.000 \\
\hline Tetra (G82.5) & 0.622 & $(0.4697362-0.824)$ & $0.00 I$ \\
\hline Para (G82.2) & 1.492 & $(1.045272-2.130)$ & 0.028 \\
\hline Hemi (G8I.9) & 0.321 & $(0.169728-0.609)$ & 0.000 \\
\hline Other & 0.772 & $(0.519638-1.147)$ & 0.200 \\
\hline
\end{tabular}

RAF = Road Accident Fund, COIDA = Compensation for Occupational Injuries and Diseases Act, ICD I0 (The International Classification of Diseases, Tenth Revision)

*One attendee was diagnosed with an upper limb injury, therefore the $\mathrm{OR}=\mathrm{I}$ and $95 \% \mathrm{Cl}$ and $\mathrm{p}$-value could not be calculated

The significant OR's were used to describe the likelihood of the variable influencing the outcome of non-attendance, in relation to a constant variable. The results of the logistic regression can be seen in Table $V$ (page 59).

Gender, employment status and age were categories that yielded insignificant results in relation to the outcome of non-attendance whereas significant results were identified within hospital classification, diagnostic category and impairment according to The International Classification of Diseases, Tenth Revision (ICD 10 coding), Hospital classification, $\mathrm{HI}$ and state department categories had OR values greater than one. Diagnostic category variable lower limb injury have an OR value greater than one. As there was only one person diagnosed with an upper limb injury who attended (see Table III page 57 ) the OR for this category was one. Spinal cord injury, CVA, TBI and Other diagnostic categories had OR values of less than one. The ICD 10 impairment coding category indicated that paraplegia was the only category that had an association with increased odds of non-attendance.

\section{DISCUSSION}

The descriptive statistics highlight similarities in the characteristic factors of both attending and non-attending patients with scheduled occupational therapy and physiotherapy appointments at outpatient clinics at WCRC. The variables are however merely associated factors and should not be considered to be predictors of attendance or non-attendance. The prediction of attendance or the reasons for non-attendance is beyond the scope of this article, which merely aimed at describing the identified factors associated with non-attendance and the odds of non- attendance in relations to certain variables.

The patient demographic factors (as depicted in Table I page 56) indicate a greater frequency and percentage of attenders, in comparison to non-attenders for all the identified categories. Firstly, the results related to gender indicate a higher frequency of both male $(59.84 \%)$ and female $(66.82 \%)$ attenders in comparison to non-attenders. As literature indicates that gender is a significant predictor of non-attendance, logistic regression was used to consider the association between the variable and the outcome of attendance. In the present study, neither the male nor female gender $(p=0.067)$ were identified as a significant factor. This contrasts with studies in which gender was identified as a factor that influenced non-attendance rates. In two studies, being female was identified as a predictor of non-attendance ${ }^{21,22}$ whereas the two studies by Ntamo et al. ${ }^{33}$ and Langhorne et al. ${ }^{8}$ found that being male was associated with non-attendance.

Furthermore, all categories within marital status had a greater frequency of attenders, which is similar to a study conducted by Shrestha and $\mathrm{Hu}^{22}$ where the authors found that patients that attended scheduled appointments were mostly married. Alternatively, age was not associated with any particular outcome. The mean age of the sample (including attenders and non-attenders) occurred in the 30-39 category. Age was not a significant variable $(p=0.697)$ associated with attendance. The results of the current study are similar to those of Maskew et al. ${ }^{21}$ who found that age was not a significant predictor of attendance. However, this is in contrast with three studies in which age was identified as a predictor of nonattendance. In these studies, results indicated that individuals being of a younger age were less likely to attend their appointments ${ }^{13,19,20}$.

Regarding socio-economic factors (as depicted in Table II page 57 ), a greater percentage of attenders had zero to four dependents whereas there was an equal distribution of attenders $(n=5)$ and non-attenders $(n=5)$ of patients who had five dependents. The largest percentage difference occurred for patients who had two dependents in which $35 \%$ of non-attenders had two dependents, in comparison to $65 \%$ of attenders. Finally, a greater frequency $(66.67 \%)$ of patients that had more than five dependents were identified as non-attenders.

Considering the employment status of the patient, more employed patients were attenders $(66.9 \%)$ whereas of the retired patients, there were $41 \%$ more patients that attended their scheduled outpatient appointments. Additionally, 654 of 837 patients were unemployed, $59.94 \%$ of unemployed patients attended their scheduled outpatient appointments. The logistic regression of employment status $(p=0.137)$ did not yield significant results and therefore, the researchers are unable to attribute employment status to the outcome of non-attendance.

The final socio-economic factor (Table II, page 57) was hospital classification. The South African Department of Health uses a hospital classification system to categorise patients according to their annual income to determine the fees that are charged to patients for medical services. A patient can either be fully subsidised by the government $(\mathrm{H} 0)$ or partially subsidised $(\mathrm{HI}-\mathrm{H} 3)$. Further classification includes full paying patients or alternatively patients that are funded by The Compensation for Occupational Injuries and Diseases Fund (COIDA), The Road Accidents Fund (RAF), Medical Aid schemes or another state department (for example, these include patients from the military). The majority of patients categorised according to hospital classifications levels were attenders, apart from patients that were categorised into state department in which there was an equal percentage of both attenders (50\%) and non-attenders (50\%).

Hospital classification $(p=0.00 \mathrm{I})$ was identified as a significant factor which influenced the odds of non-attendance (Table $V$, page 59). A hospital classification of $\mathrm{HO}$ was identified as a comparative category. The results indicated that patients that were categorised as $\mathrm{H} 2(\mathrm{OR}=.264)$ or Medical Aid $(\mathrm{OR}=.4 \mathrm{I} 3)$ had a lower association with the outcome of non-attendance and were therefore less likely to not attend their scheduled occupational and physiotherapy outpatient appointments. Patients that were classified under HO (and therefore fall into a lower socio economic class) were more likely to be non-attenders which is confirmed in a study conducted by Mitchell and Selmes ${ }^{18}$ in which socio-economic status and absence of health insurance was associated with non-attendance.

According to the diagnostic variables (as depicted in Table III, page 57) there was a greater percentage of attenders for all diagnostic categories. Spinal cord injuries was the diagnosis that occurred 
most among both the attenders $(n=283)$ and the non-attenders $(n=227)$. Furthermore, diagnostic category $(p=0.000)$ was found to have a significant association with non-attendance. Patients that had a classification of a CVA $(O R=.268)$ or Other $(O R=.469)$ had lower odds of non-attendance, in comparison to patients with spinal cord injuries. The classification of Other included diagnoses such as: Cerebral Palsy, neuropathies, muscular dystrophies and Spina Bifida. Patients diagnosed with CVA or Other, were therefore less likely to not attend their scheduled appointments at WCRC. The ICD IO as used by WCRC, is a diagnostic classification standard that is utilised for clinical and research purposes and assists with evidence based decision making, comparing health information and data across different time periods and between health care practice settings. This category indicated that more patients with a classification of: tetraplegia (61.65\%), paraplegia (5I.86\%), hemiplegia $(83.33 \%)$ and other $(67.56 \%)$ were attenders. Furthermore, impairment according to ICD I0 coding $(p=0.000)$ was significantly associated with non-attendance. Patients that had a classification of paraplegia $(O R=1.492)$ were more likely to be non-attenders than patients that had a classification of tetraplegia. Patients with a classification of hemiplegia $(O R=.322)$ had a lower association with the odds of non-attendance and were therefore less likely to not attend appointments, in comparison with patients that had a classification of tetraplegia.

Moreover, mechanism of injury, which included categories of other (assault and work related injuries) and not applicable (patients diagnosed with Cerebral Palsy or CVA) had a greater percentage of attenders than non-attenders for the majority of categories. Stabbing, however, was identified as an isolated category in which most of the patients were non-attenders (53.25\%).

Considering comorbidities, patients that were non-attenders had a higher frequency of respectively being underweight (66.67\%), a diagnosis of Diabetes Mellitus (57.14\%) or a Malignancy (100\%) whereas there was an equal distribution of attending and nonattending patients that were diagnosed with active Tuberculosis $(n=4)$. We are however hesitant in associating comorbidities with the study population as documentation in the patient medical files was inconsistent, particularly with regards to the comorbidities section. For example, of the 837 patients included in the study, 293 patients were noted to have no comorbidities whereas 193 were noted as not applicable. The comorbidities results may thus not be reliable. The review of literature however did not highlight any known relationship between the comorbidity variables (Table III, page 57) and attendance or non-attendance.

The geographic factors (Table IV, page 58) of non-attenders included residing in the Cape Winelands, Overberg and West Coast regions. These geographic factors may be attributed to non-attenders due to further travelling distance between the respective regions and the WCRC. The results of the study are similar to study the by Ngwenya et al. ${ }^{26}$ in which it was identified that patients who live far away or had a greater travelling distance to the clinic were more likely to miss their appointments. Furthermore, a total of eight patients did not reside in the Western Cape Province, of which there was an equal distribution of attenders ( $\mathrm{n}$ $=4)$ and non-attenders $(n=4)$. Additionally all sources of referral had a higher frequency of attenders than non-attenders with the majority of attenders $(n=191)$ and non-attenders $(n=125)$ being referred from tertiary level health institutions. This contrasts with the results of Marzolini et al's study 34 in which there were no significant statistical results indicating the source of the referral as a predictor of non-attendance. According to factors related to time it is evident that spring was the season in which the highest rates of non-attendance occurred (38\%). Summer, however, had equal attendance and non-attendance rates whereas winter and autumn had higher attendance rates. Considering the attendance rates during the months of the year, the researchers identified that attendance rates were higher than non-attendance rates during the first six months of the year (January - June) and contrastingly, non-attendance rates were higher during the last six months of the year (July-December).

August was an exception, however, as the attendance rates were higher (4\%). It was also identified that November had the highest rate of non-attendance (I $14 \%)$. The greatest differences between attendance and non-attendance occurred in June with I $2 \%$ more attendance than non-attendance and in July, September and November where there was $8 \%$ higher non-attendance. Considering week days and weeks of the month, Thursdays had the highest non-attendance rates $(28 \%)$ as well as the 4 th week of the month (26\%). Similarly to the study by Ellis and Jenkins ${ }^{16}$, attendance was highest on a Friday. Higher attendance rates were also associated with attendance during the fourth week of the month.

Overall, the results indicated that more variables (as indicated in tables I-5) presented with a greater frequency and percentage of attenders, in comparison to non-attenders. Isolated factors were however identified in which there was a greater frequency of non-attenders. These factors included: patients having more than five dependents (see Table II page 57), stabbing as a mechanism of injury and co-morbidities of, Diabetes Mellitus, Malignancy or being underweight, respectively (see Table III page 57). Considering geographic factors, a greater frequency of non-attenders resided in the Cape Winelands, Overberg and West-Coast regions (see Table IV page 58). Patients residing in these regions have to travel further to attend appointments at the WCRC. Additionally, there was a higher number of non-attenders in spring, and in the last six months of the year, particularly in November with more nonattenders on Thursdays and in the fourth week of the month. The logistic regression performed on selected variables, indicated that hospital classification, diagnostic category and ICD- 10 impairment coding had a significant $(\mathrm{p}>0.05)$ association with attendance.

\section{Limitations}

There were several limitations. Firstly, the researchers were unable to accurately analyse and associate co-morbidities with non-attendance due to conflicting record keeping with regards to this variable. Furthermore, Cerebral Palsy (CP) was a frequently occurring diagnosis, which may have delivered significant results. However, CP was categorised within the other diagnostic category as per the convention of the institution and therefore researchers were unable to make conclusions regarding cerebral palsy and its association with non-attendance. During data collection and analysis the researchers were unable to accommodate for confounding variables (such as the economic climate or socio-political context during the time period January-December 2017) due to the nature of the study and were therefore not able to identify predictors of non-attendance. As a result, only univariate associations were made with non-attendance.

\section{RECOMMENDATIONS}

Future research should consider similar study designs at different health care practice settings in South Africa offering inpatient rehabilitation followed by outpatient services. Factors such as patient access to transport, support systems and caregivers, home language and use of assistive devices should be considered in these studies, as literature indicates that these factors may influence non-attendance. Further studies will contribute to the generalisability of results to similar institutions and will add to the body of knowledge on this topic within the South African context. In addition, reasons for non-attendance should be explored further to assist the institution in reducing non-attendance rates. Researchers should consider the significant factors: hospital classification, diagnostic category and ICD-I0 impairment coding, as identified in the current study.

\section{CONCLUSION}

Patient non-attendance directly affects patients, health-care institutions and the government. Non-attendance may have negative 
implications on patient health and may result in financial disruption for institutions and government funders. A review of the literature indicated that limited research exists regarding factors associated with non-attendance, specifically within a South African context. The current study provides useful insights into the factors associated with non-attendance of outpatients to scheduled occupational therapy and physiotherapy appointments at the Western Cape Rehabilitation Centre. The results of the study indicated that hospital classification, diagnostic category and impairment according to ICD IO coding were factors that had a significant association with non-attendance. However, further studies are needed to determine the reasons for non-attendance at institutions such as WCRC which will assist the institutions in implementing solutions to reduce high rates of non-attendance.

\section{REFERENCES}

I. Finkelstein V. Rehabilitation services. Available from: https://www.westerncape.gov.za/service/rehabilitation-services

2. Schultz-Krohn W, Mchugh Pendleton H. Application of the Occuaptional Therapy Practice Framework to Physical Dysfunction. In: Pedretti's Occupational Therapy: Practice Skillls for Physical Dysfunction. 2013: 28-54.

3. Jin J, Sklar GE, Oh VM Sen, Li SC. Factors affecting therapeutic compliance: A review from the patient's perspective. Ther Clin Risk Manag. 2008; 4(I): 269-86. https://doi.org/10.2147/tcrm.s|458

4. Collins J, Santamaria N, Clayton L. Why outpatients fail to attend their scheduled appointments: a prospective comparison of differences between attenders and non-attenders. Aust Heal Rev. 2003; 26(I): 52-63.

https://doi.org/10.107I/AH030052

5. Lee V], Earnest A, Chen MI, Krishnan B. Predictors of failed attendances in a multi-specialty outpatient centre using electronic databases. BMC Health Serv Res. 2005; 5 (5I).

https://doi/I0.I |86/|472-6963-5-5 I

6. Rhoda A, Mpofu R, De Weerdt W. Activity limitations of patients with stroke attending out-patient facilities in the Western Cape, South Africa. South African J Physiother. 201 I; 67(2): 16-22. https://doi.org/10.4I02/sajp.v67i2.4I

7. Duncan PW, Horner RD, Reker DM, Samsa GP, Hoenig H, Hamilton $B$, et al. Adherence to Postacute Rehabilitation Guidelines Is Associated With Functional Recovery in Stroke. Stroke. 2002; 33: 167-78. https://doi.org/10.1161/hs0102.101014

8. Langhorne P, Bernhardt J, Kwakkel G. Stroke rehabilitation. Lancet. 20II; 377(9778): 1693-702 https://doi.org 10.1016/S0I40-6736(I I)60325-5

9. Seekins T, Clay J, Ravesloot C. A Descriptive Study of Secondary Conditions Reported by a Population of Adults with Physical Disabilities Served by Three Independent Living Centers in a Rural State. J Rehabil. 1994: 47-5I.

10. Adler C. Spinal Cord Injury. In: Pedretti's Occupational Therapy: Practice Skillls for Physical Dysfunction. 7th ed. 2013: 954-82.

II. George A, Rubin G. Non-attendance in general practice: A systematic review and its implications for access to primary health care. Fam Pract. 2003; 20(2): I78-84.

http://dx.doi.org/10.1093/fampra/20.2.178

12. Bech $M$. The economics of non-attendance and the expected effect of charging a fine on non-attendees. Health Policy (New York). 2005; 74: |8|-9| http://dx.doi.org/10.1016/j.healthpol.2005.01.00I

13. Frankel S, Farrow A, West R. Non-attendance or non-invitation? A case-control study of failed outpatient appointments. Br Med J. 1989; 298(6684): 1343-5. https://doi.org 10.1 |36/bmj.298.6684.1343

14. Mbada CE, Ajayi O, Agbeja OB, Mbada KA, Awotidebe TO, Oghumu SN. Non-attendance for out-patient physiotherapy: Evaluation, prediction and physiotherapists' perceptions- a cross-sectional study. J Phys Ther. 2013; 7(I): 12-22.

15. Ponsford JL, Olver JH, Curran C. A profile of outcome: 2 years after traumatic brain injury. Brain Inj. 1995; 9(I): I-10. http://dx.doi.org/10.3 I09/02699059509004565

16. Ellis DA, Jenkins R. Weekday Affects Attendance Rate for Medical
Appointments: Large-Scale Data Analysis and Implications. PLoS One. 2012; 7(I2). https://doi/org/ 10.137//journal.pone.005। 365

17. Hamilton W, Round A, Sharp D. Patient, hospital, and general practitioner characteristics associated with non-attendance: A cohort study. Br J Gen Pract. 2002; 52(477): 317-9. https://doi.org/ I 194245 I

18. Mitchell AJ, Selmes T. A Comparative Survey of Missed Initial and Follow-Up Appointments to Psychiatric Specialties in the United Kingdom. Psychiatr Serv. 2007; 58(6): 868-7I. http://dx.doi.org// 0.I I 76/ps.2007.58.6.868

19. Worcester MUC, Stojcevski Z, Murphy B, Goble AJ. Factors associated with non-attendance at a secondary prevention clinic for cardiac patients. Eur J Cardiovasc Nurs. 2003; 2(03): I 5 |-7.| https://doi.org/I0.1016/SI474-5I5I(03)0003I-8

20. Mbada CE, Nonvignon J, Ajayi O, Dada OO, Awotidebe TO, Johnson OE, et al. Impact of missed appointments for out- patient physiotherapy on cost, efficiency, and patients ' recovery. Hong Kong Physiother J. 20I3; 3I(I): 30-5. https://doi.org/ 10.1016/j.hkpj.2012.12.001

2I. Maskew M, MacPhail P, Menezes C, Rubel D. Lost to follow up: contributing factors and challenges in South African patients on antiretroviral therapy. South African Med J. 2007; 97(9): 853-7.

22. Shrestha MP, Hu C, Taleban S. Appointment Wait Time, Primary Care Provider Status, and Patient Demographics are Associated With Nonattendance at Outpatient Gastroenterology Clinic. J Clin Gastroenterol. 20I7; 5I(5): 433-8. https://doi.org/ 10.1097/MCG.0000000000000706

23. Alexandre NMC, Nordin M, Hiebert R, Campello M. Predictors of compliance with short-term treatment among patients with back pain. Pan Am J Public Heal. 2002; I 2(2): 86-95. http://dx.doi.org/I0.1590/S 1020-49892002000800003

24. Sharp DJ, Hamilton W. Non-attendance at general practices and outpatient clinics. Br Med J. 200I; 323(732I): I08I-2. https://doi.org/ I0.1 |36/bmj.323.732I.1081

25. Herrick J, Gilhooly MLM, Geddest DAM. Non-attendance at periodontal clinics: forgetting and administrative failure. J Dent. 1994; 22(5): 307-9. http://dx.doi.org/10.1016/0300-5712(94)90068-X

26. Ngwenya B, Van Zyl D, Webb E. Factors influencing non-attendance of clinic appointments in diabetic patients at a Gauteng hospital in 2007 / 2008. J Endocrinol Metab Diabetes South Africa. 2009; 14(2): $106-10$.

http://dx.doi.org/10.1080/22201009.2009.10872203

27. Kahonde C, Mlenzana N, Rhoda A. Persons with physical disabilities 'experiences of rehabilitation services at community health centres in Cape Town. South African J Physiother. 2010; 66(3): I-7. https://doi.org/ I0.I3 |40/RG.2.I.I687.9204

28. Lieberman L, Meana M, Stewart D. Cardiac Rehabilitation : Gender Differences in Factors Influencing Participation. J Women's Heal. 1998;7(6): 717-23.

29. Western Cape Rehabilitation Centre. https://www.wcrc.co.za

30. OECD. Glossary of Statistical Terms. 2005. https://stats.oecd.org > glossary

31. UK Data Service. Legal and Ethical - Data Management. 2017. https://www.ukdataservice.ac.uk/media/604797/2017-05-24_02_legal_ethical_issues_in_sharing_data.pdf

32. Szumilas M. Explaining Odds Ratios. 2010: 227-9. PMID: 20842279; PMCID: PMC2938757.

33. Ntamo N P, Buso D, Longo-Mbenza B. Factors affecting poor attendance for outpatient physiotherapy by patients discharged from Mthatha General Hospital with a stroke. SA J Physiother. 20 I3; 69(3): 19-24. http://dx.doi.org/10.4102/sajp.v69i3.29

34. Marzolini S, Balitsky A, Jagroop D, Corbett D, Brooks D, Grace SL, et al. Factors Affecting Attendance at an Adapted Cardiac Rehabilitation Exercise Program for Individuals with Mobility Deficits Poststroke. J Stroke Cerebrovasc Dis. 2016; 25(I): 87-94. https://doi.org/ 10.1016/j.jstrokecerebrovasdis.2015.08.039

\section{AUTHOR ROLES}

SdK refined the research question, supervised the students during execution of the research, assisted in writing up the research 
report, drafted the article and worked on revisions of subsequent drafts. LE conducted the research, assisted in writing the research report, assisted with drafting the article and worked on revision of subsequent drafts. $\mathrm{ZN}$ conducted the research, assisted in writing the research report and assisted with drafting the article. $A B, M C$, $M S$ and SMMZ conducted the research and assisted in writing the research report.

\section{Corresponding Author}

\section{Susan De Klerk}

Sdk@sun.ac.za 